\title{
A teoria contemporânea do restauro e as cerâmicas arqueológicas da Amazônia
} Contemporary theory of restoration and the Amazon archaeological ceramics

\author{
Lorena Porto Maia (D) | Thais Alessandra Bastos Caminha Sanjad (D) | Helena Pinto Limall (D) \\ Universidade Federal do Pará. Belém, Pará, Brasil \\ "Museu Paraense Emílio Goeldi. Belém, Pará, Brasil
}

\begin{abstract}
Resumo: Este artigo apresenta uma discussão acerca das intervenções de conservação e restauro realizadas em cerâmicas arqueológicas, com ênfase no acervo do Museu Paraense Emílio Goeldi (MPEG), localizado em Belém, Pará, região Norte do Brasil. A pesquisa tem como principal objetivo a identificação dos tipos de restauro encontrados na reserva técnica do MPEG e a aplicabilidade da teoria contemporânea do restauro na intervenção da cerâmica arqueológica. Para o desenvolvimento da pesquisa, foram analisadas as principais teorias de restauro e políticas preservacionistas do Brasil. Em seguida, reconheceu-se os valores culturais das cerâmicas arqueológicas e seu significado para a sociedade civil. Por fim, foram analisadas as intervenções restaurativas identificadas no acervo do MPEG, de modo a discutir sua trajetória ao longo do tempo. Ademais, debate-se sobre as reflexões pré-intervenções necessárias, de modo a determinar a intenção da restauração e as técnicas ideais para a salvaguarda do bem cultural.
\end{abstract}

Palavras-chave: Cerâmica arqueológica. Conservação e restauro. Arqueologia amazônica. Acervo cerâmico.

Abstract: This paper presents a discussion about conservation and restoration interventions carried out on archaeological ceramics with emphasis on the collection of the Museu Paraense Emilio Goeldi (MPEG), located in Belém, Pará, northern Brazil. The main objective of this research is to identify the types of restoration found in the MPEG technical reserve and the applicability of the Contemporary Restoration Theory in the intervention of archaeological ceramics. For the development of the research, the main restoration theories and preservationist policies of Brazil were analyzed. Then the main cultural values of archaeological ceramics were recognized and their significance for civil society. Finally, the restorative interventions identified in the MPEG collection were analyzed in order to discuss their trajectory over time. In addition, it discusses the necessary pre-intervention reflections to determine the intention of restoration and the ideal techniques for safeguarding the cultural heritage.

Keywords: Archaeological ceramics. Conservation and restoration. Amazon archeology. Ceramic collection.

Maia, L. P., Sanjad, T. A. B. C., \& Lima, H. P. (2021). A teoria contemporânea do restauro e as cerâmicas arqueológicas da Amazônia. Boletim do Museu Paraense Emílio Goeldi. Ciências Humanas, 16(1), e20190085. doi: 10.1590/2178-2547-BGOELDI-2019-0085

Autora para correspondência: Lorena Porto Maia. Universidade Federal do Pará. Rua Augusto Corrêa. Belém, PA, Brasil. CEP 66075-110 (lore.portomaia@gmail.com).

Recebido em 17/10/2019

Aprovado em 10/08/2020

Responsabilidade editorial: Cristiana Barreto 


\section{INTRODUÇÃO}

As cerâmicas foram amplamente utilizadas por diversos povos indígenas que ocuparam a região amazônica por milênios, tanto para atividades domésticas quanto para rituais. Sendo a cerâmica um material relativamente estável, em função do tratamento térmico pelo qual passou durante sua produção, que resulta em peças duráveis e capazes de sobreviver por centenas ou milhares de anos, esta categoria de artefatos é, frequentemente, o testemunho material mais evidente das antigas culturas da Amazônia (H. Lima et al., 2016).

As cerâmicas arqueológicas materializam importantes informações acerca de um povo. São mais que um reflexo da agência humana, pois, em muitos contextos indígenas, elas participam da estruturação da vida social e representam mediadores importantes para as relações entre indivíduos e grupos dentro dos coletivos (Van Velthem, 2012). Logo, todas as informações relacionadas a estas peças, desde as características dos materiais até marcas e sujidades encontradas na superfície, são fundamentais para a interpretação de prováveis procedências, assim como de informações acerca de quem as produziu e as utilizou, tais como sobre modos de viver, tipos de alimentação, formas de organização social e religiosidade, formando, assim, valiosos aportes sobre identidades e para o reconhecimento da diversidade cultural dos povos ameríndios.

Enquanto evidências materiais da cultura, as cerâmicas persistem no centro das atenções e atraem diferentes estudos que têm estruturado e consolidado distintos campos de conhecimento (Bruno, 2009). A preservação deste material abrange diversas áreas, como: Arqueologia, Ciência da Conservação, História, Química, entre outras. Estes campos atuam em conjunto em todas as etapas deste processo, o qual se inicia mesmo antes da coleta nos sítios arqueológicos, quando os parâmetros de recuperação dos vestígios são determinados, passando pela fase das escavações em campo até o período póscampo, desenvolvido principalmente em laboratórios e reservas técnicas de museus e universidades (Guetti, 2015).
Estas atividades são indissociáveis das informações relacionadas a esses campos e devem salvaguardar todo o potencial analítico da peça, permitindo o estudo abrangente das características desses materiais, da simbologia e do significado para os povos aos quais fizeram parte, seja no passado, seja no momento contemporâneo, dado que muitas comunidades amazônicas se relacionam e interagem de maneira muito intensa com o patrimônio arqueológico, formando, inclusive, coleções domésticas (Bezerra, 2011; H. Lima \& Moraes, 2013).

As intervenções de conservação e restauro em cerâmicas arqueológicas estiveram por muito tempo direcionadas apenas para a questão formal da peça, ou seja, seu principal objetivo era a reconstituição do volume do objeto. Essas intervenções eram facilmente identificáveis e buscavam representar o estado em que o objeto arqueológico foi encontrado, assim como a sua provável forma original completa. A intervenção conhecida por restauro arqueológico aplicado a partes de bens culturais edificados na Itália, e que teve início durante o primeiro terço do século XIX, reconstituía peças de edificações (colunas, arquitraves, entre outros) a partir de achados arqueológicos. Essa maneira de intervir deixava visíveis as emendas e, no caso de necessitar de preenchimento de lacunas, essas eram feitas com materiais diferentes ou mesmo de forma simplificada (Kuhl, 2006).

Ainda nesse período, duas teorias antagônicas tiveram grande reconhecimento: o Restauro Estilístico de Viollet Le Duc, na França, e o Restauro Romântico de Jon Ruskin, na Inglaterra. O primeiro buscava a autenticidade da obra e a pureza do estilo gótico, mesmo que para isso fosse necessário intervir e acrescentar novas formas. $\bigcirc$ segundo era conservador e defendia a não intervenção nos monumentos. Outras teorias, como a de Camilo Boito (Restauro Moderno) e a de Gustavo Giovannonni (Restauro Histórico), ambas iniciadas na Itália, foram de grande importância para o desenvolvimento do pensamento preservacionista do século XIX (Kuhl, 2006).

A principal teoria do restauro do século $X X$ é a teoria do restauro de Cesare Brandi, publicada em 1963. 
Segundo o autor, esta teoria deveria ser aplicada para obras de artes, diferenciando, assim, o restauro das atividades de reparação. É embasada em dois principais axiomas, o primeiro ratifica a importância da identificação do objeto como obra de arte, o segundo refere-se à busca a um estado original, chamado de ". . . unidade potencial da obra de arte ...." (Brandi, 2013, p. 33). Ainda no segundo princípio, fortalece a necessidade de não cometer um falso artístico ou histórico'. Brandi (2013) considera que o que se restaura é a matéria, e não a imagem do objeto (Kuhl, 2006).

Esta teoria foi utilizada por dezenas de anos para pinturas, esculturas e mesmo na arquitetura. No entanto, alguns objetos foram deixados de fora dessa análise. Braga $(2004,2006)$ faz uma importante análise acerca dessa concepção e sobre sua aplicabilidade para objetos arqueológicos e etnográficos. Seu texto propõe reflexões a respeito desses artefatos que, apesar de não pertencerem ao seleto grupo de obras de arte, podem apresentar características semelhantes a esses objetos. Nesse aspecto, Braga (2006) reflete a respeito da 'epifania da imagem' dos objetos arqueológicos e etnográficos e da intensa relevância cultural desses objetos, que pode ser traduzida nos seus aspectos artísticos e históricos. Por fim, o autor conclui que esses artefatos, dentro de um contexto museológico, também estão sob o mesmo regime de exceção que as obras de arte, portanto, o termo restauro pode ser aplicado para intervenções visando à salvaguarda dos mesmos.

Um exemplo deste tipo de intervenção pode ser observado em algumas cerâmicas arqueológicas que compõem a reserva técnica do Museu Paraense Emílio Goeldi (MPEG), nas quais os fragmentos eram consolidados com emendas visivelmente diferenciadas e a reconstituição formal de lacunas era realizada com materiais de texturas e cores diferentes do original (Figura 1).

A teoria contemporânea do restauro (TCR) traz uma análise diferente do patrimônio cultural quanto à sua conservação e ao seu restauro, pois passa a abordar a natureza subjetiva do restauro. Segundo esta teoria, restauram-se determinados valores inerentes ao objeto, e não apenas a sua matéria em uma suposta objetividade. Ao contrário, entendendo que esses valores são culturalmente relativos, a teoria ressalta que cabe ao restaurador avaliar e destacar sua intenção ao intervir num objeto. A sociedade passa a ser abordada também como uma categoria ativa e que deve ser respeitada, ou seja, sua interação com o patrimônio e seu reconhecimento devem ser considerados no momento da intervenção. Amplia também as teorias clássicas do restauro, ao identificar que o foco não é o bem em si, e sim sua memória, seus valores simbólico e historiográfico (Viñas, 2010).

Esta pesquisa teve como objetivo a identificação dos tipos de restauro encontrados no acervo arqueológico salvaguardado no MPEG, bem como a aplicabilidade da TCR na intervenção deste material. O desenvolvimento do trabalho foi realizado por meio da análise dos valores patrimoniais intrínsecos às cerâmicas arqueológicas, tal como discutido

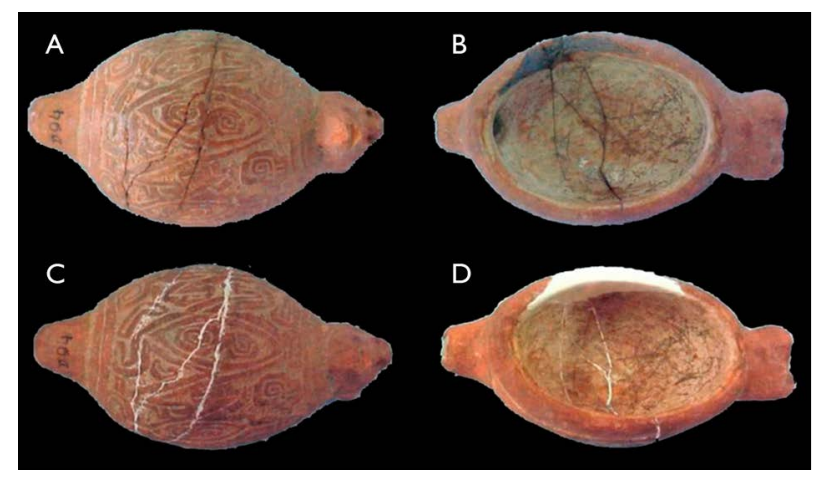

Figura 1. Inalador zoomorfo (número de tombo D-94) da cultura Marajoara, comodato do governo do estado do Pará. Peça restaurada em 2002. A) Vista superior da peça após a montagem dos fragmentos resgatados; B) vista interna da peça após a montagem dos fragmentos resgatados; C) vista superior da peça após a intervenção restaurativa; D) vista interna da peça após a intervenção restaurativa. Fonte: resumo do trabalho de tratamento e conclusão das peças do governo do estado, 2002. Acervo de documentação da Reserva Técnica Mário Ferreira Simões, Ministério da Ciência, Tecnologia e Inovações/Museu Paraense Emílio Goeldi (MCTI/MPEG) (2002).

A restauração deve visar ao restabelecimento da unidade potencial da obra de arte, desde que isso seja possível, sem cometer um falso artístico ou um falso histórico, e sem cancelar nenhum traço da passagem da obra de arte no tempo (Brandi, 2013, p. 33).

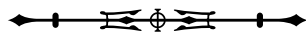


em teorias clássicas da restauração (Boito, 2008; Brandi, 2013; Riegl, 2014), nos estudos de coleções de cerâmicas arqueológicas (Braga \& Queiroz, 2000; Braga, 2006; Bouyer, 2010; S. Lima, 2002, 2016) e, principalmente, pela TCR, que subsidia o presente texto. Em seguida, foram analisados os relatórios de intervenção e documentação do acervo em questão², bem como as características físicas das peças inteiras selecionadas que tenham passado por intervenções de conservação e restauro existentes na reserva técnica.

O Museu Goeldi é o segundo museu mais antigo do Brasil e a mais antiga instituição científica da Amazônia. Detém um acervo arqueológico de quase duas milhões de peças, sendo a grande maioria delas composta de objetos cerâmicos. Podem ser encontrados na reserva técnica diferentes tipos de intervenção realizados ao longo dos mais de 150 anos de desenvolvimento em pesquisas da instituição (Van Velthem et al., 2019).

A coleção arqueológica do MPEG (Figuras 2 e 3) guarda em seus componentes materiais uma importante história da conservação e do restauro em peças arqueológicas praticada na Amazônia, com exemplares de técnicas restaurativas diferenciadas ao longo do tempo. Logo, apresenta uma interessante trajetória para a conservação e o restauro de cerâmicas arqueológicas.

\section{A COLEÇÃO ARQUEOLÓGICA E A RESERVA TÉCNICA DO MUSEU PARAENSE EMÍLIO GOELDI}

As coleções de arqueologia e etnografia do Museu Goeldi são tombadas pelo Instituto do Patrimônio Histórico e Artístico Nacional (IPHAN) como patrimônio cultural do Brasil desde a década de 1940; elas são as primeiras coleções arqueológicas tombadas no país ( $\mathrm{H}$. Lima et al., 2018; Van Velthem et al., 2019). Após 150 anos de história de pesquisa arqueológica, o acervo arqueológico do Museu Goeldi conta hoje com mais de três mil objetos inteiros

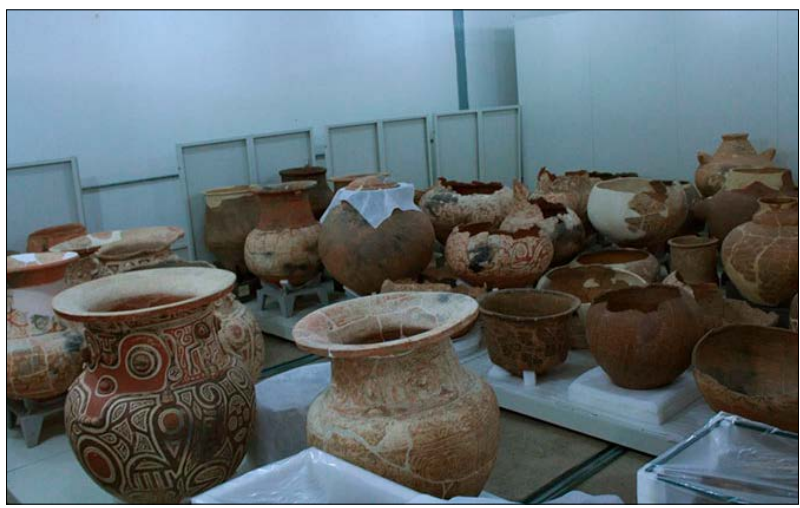

Figura 2. Parte da coleção de cerâmicas arqueológicas da Reserva Técnica Mário Ferreira Simões, MCTIC/MPEG. Foto: Lorena Porto Maia (2019).

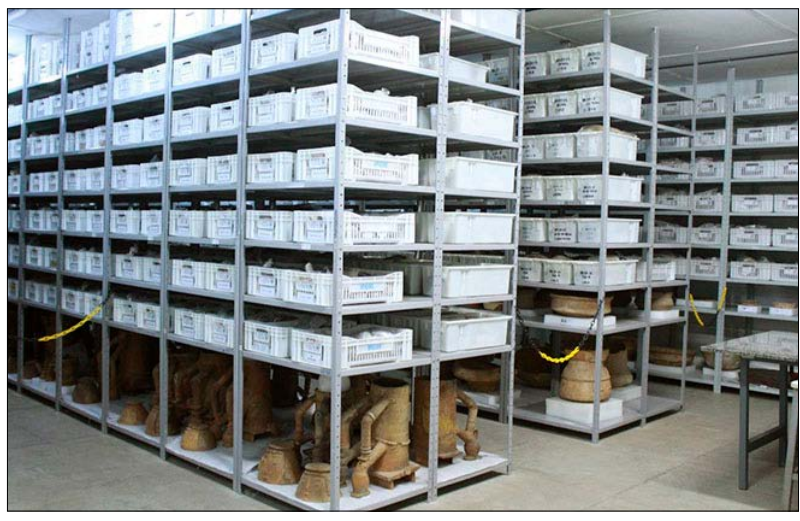

Figura 3. Estantes de ferro utilizadas para organização do material cerâmico arqueológico da Reserva Técnica Mário Ferreira Simões, MCTIC/MPEG. Foto: Lorena Porto Maia (2019).

ou semi-inteiros e milhões de fragmentos cerâmicos e líticos, além de uma considerável quantidade de material ósseo, botânico e malacológico (H. Lima et al., 2018). Trata-se de um acervo excepcional, com itens que atestam a sociobiodiversidade e a complexidade da longa história da ocupação humana da Amazônia, desde suas manifestações mais antigas que remontam a milhares de anos e reverberam até os contextos mais recentes, coloniais e pós-coloniais. Tendo estes materiais entrado no Museu em circunstâncias históricas e científicas bastante distintas,

\footnotetext{
2 Tivemos acesso integral ao banco de dados de restauro da Reserva Técnica Mário Ferreira Simões (RTMFS/MPEG), bem como aos relatórios que constam no setor de documentação (RTMFS/MPEG, n.d., 2002; Freitas \& Braga, n.d.; Dos Santos, 2010; Simas, 2017a, 2017b; Araújo, 2019a, 2019b).
}

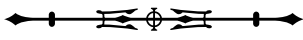


seu tratamento curatorial foi, portanto, realizado de forma desigual e com objetivos diferentes. Isso confere ao acervo arqueológico uma enorme potencialidade para gerar conhecimento em distintos campos do conhecimento, como a Museologia, a Conservação e o Restauro.

A Reserva Técnica de Arqueologia Mário Ferreira Simões (RTMFS) é o local de guarda deste numeroso e diversificado acervo, onde a equipe de curadoria desenvolve continuamente ações de gerenciamento, conservação e comunicação, entendendo, inclusive, que a salvaguarda envolve a responsabilidade do museu em permitir o acesso às coleções, publicar informações e cuidar do patrimônio, resguardando sua segurança (Simas et al., 2019).

De acordo com o levantamento realizado por Araújo (2019a, 2019b)3), desde 1980 até 2019, as coleções do Museu Goeldi participaram de 108 exposições em várias cidades brasileiras e pelo mundo, entre as quais 25 tinham foco nas cerâmicas arqueológicas. Destacam-se, entre outras: o lançamento, na própria instituição, do "Catálogo do Banco Safra" (ver MPEG, 1986), que visibilizou muitos dos 'highlights' da coleção que seriam posteriormente apresentados em outras mostras; o " $V$ centenário do descobrimento da América" (1986-1987), na Espanha; "Amazônia e tecnologia" (1998), no Museu do Louvre, em Paris; "Brasil 500 anos mostra do redescobrimento" (2000-2001), que circulou entre várias cidades; a "Unknown Amazon" (2001-2002), no Museu Britânico de Londres; "Amazonia Native Traditions" (2004), no Museu Imperial da Cidade Proibida, em Pequim, na China. As peças escolhidas para essas mostras foram, em geral, aquelas com maior 'legibilidade' a um público, ou seja, peças com forte apelo estético, seja pelas representações, seja pelas técnicas, e ainda objetos mais completos (inteiros ou restaurados). Logo, verifica-se certa redundância nas peças escolhidas pelos curadores, com destaque às peças Marajoara, Santarém, Aristé e Maracá, que compõem uma parcela significativa da coleção.
Particularmente, a exposição "Unknown Amazon" (UA) foi acompanhada por uma iniciativa de restauro em um grande número de peças e representou, para a coleção arqueológica do MPEG, grande avanço, já que o projeto previa, além das intervenções in loco, a capacitação de equipe técnica e de estagiários na própria instituição. Segundo o relatório do projeto, 58 peças sofreram intervenções, algumas delas de alta complexidade (Freitas \& Braga, n.d.). Ainda segundo o relatório, a grande maioria das restaurações priorizou a reintegração cromática e pictórica para fins expositivos, em algumas com apresentação estética com pontilhado sobre a cerâmica original, refazendo o desenho nas áreas de perda do mesmo.

Depois deste vultuoso projeto, outra coleção particularmente intervencionada foi a de 48 peças marajoaras provenientes do espólio de Dita Acatauassu, encaminhadas ao MPEG pelo IPHAN (Dos Santos, 2010), e que foi posteriormente retrabalhada por Simas (2017a), com o objetivo de obter a guarda definitiva pelo MPEG. Ressaltamos, ainda, uma peça da coleção Curt Nimuendajú (Figura 4), selecionada por critérios de relevância histórica e arqueológica, bem como por necessidades expositivas, cujo restauro seguiu o critério de intervenção mínima e reversibilidade, utilizando reintegração cromática de forma minimizada apenas nas áreas de preenchimento (Simas, 2017a).

A coleção do Museu Goeldi é como uma memória das técnicas de restauro em cerâmicas arqueológicas da Amazônia (ver RTMFS/MPEG, 2002; Dos Santos, 2010), e incorpora em suas peças os principais momentos dessas intervenções. Por isso, também sua curadoria tem investido no estabelecimento de normas e procedimentos de conservação preventiva, entendendo que esses bens culturais devem ser usufruídos no presente, continuamente lidos, estudados e reinterpretados, e igualmente transmitidos às novas gerações em suas dimensões físicas e imateriais (Simas, 2017b).

\footnotetext{
As informações coletadas no Arquivo Guilherme De La Penha, na Biblioteca Domingos Soares Ferreira Penna e nos arquivos da RTMFS são referentes ao trabalho realizado nos meses de abril e maio de 2019 por Lucas Monteiro de Araújo, como parte das pesquisas do projeto de doutorado em Antropologia Social da Universidade Federal do Pará (UFPA), intitulado "O que os viajantes levaram? Narrativas da cultura material Marajoara em museus nacionais e internacionais", ainda em desenvolvimento. $O$ uso dos dados foi autorizado pelo autor.
}

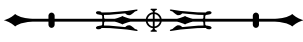




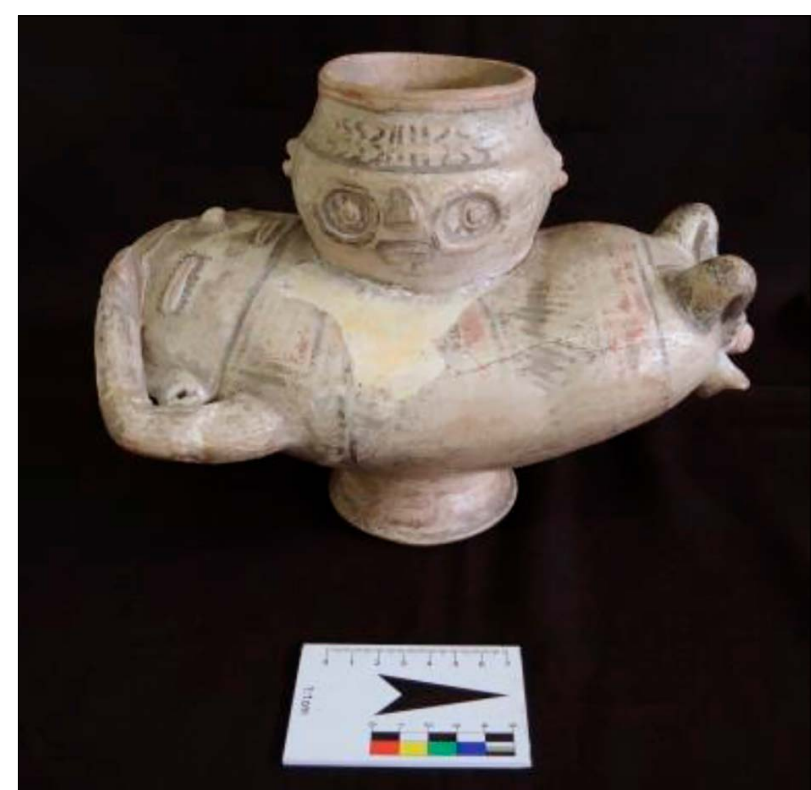

Figura 4. Vaso antropomorfo (número de tombo T-324) da cultura Santarém. Peça restaurada em 2017, a qual compõe a Reserva Técnica Mário Ferreira Simões, MCTIC/MPEG. Procedência: Santarém, Pará. Coleção Curt Nimuendajú. Fonte: Simas (2017a).

Ressaltamos, ainda, a multiplicidade de leituras possíveis sobre a coleção, que devem ser garantidas aos públicos diferenciados. Sendo as cerâmicas arqueológicas do acervo do MPEG eminentemente de origem indígena précolonial, entendemos os povos indígenas contemporâneos como detentores, por excelência, deste patrimônio. Como bem nos lembra Van Velthem (2019), apesar da exposição midiática e da divulgação em mostras em museus, as culturas indígenas e suas estéticas permanecem ainda pouco conhecidas para a maioria dos brasileiros. Essas estéticas são ". . . concebidas e formuladas em contextos específicos, histórica e geograficamente diferenciados, e estão inseridas em múltiplas dimensões, simbólicas, cosmológicas, sociais, sendo culturalmente definidas e direcionadas para o cumprimento de um papel ativo na vida de seus produtores" (Van Velthem et al., 2019, p. 17). Argumentamos, então, que ações de curadoria, de conservação preventiva, bem como as intervenções restaurativas na RTMFS devem ter, como princípio, a discussão e o entendimento da pluralidade de 'valores' inerentes aos objetos.

\section{OS VALORES PATRIMONIAIS DAS CERÂMICAS ARQUEOLÓGICAS}

O termo 'valor' é utilizado desde as teorias clássicas da conservação e do restauro e teve como marco de discussão a obra "O culto moderno dos monumentos: a sua essência e origem", de Riegl (2014), que conceitua e debate acerca dos valores de antiguidade, histórico, de rememoração

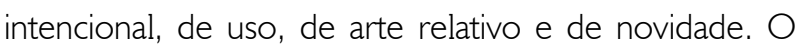
conceito é ampliado com a teoria contemporânea do restauro, ao entender que esses valores são dinâmicos, logo, possuem significações e ressignificações ao longo do tempo para diferentes setores da sociedade. Na sua obra, Viñas (2010) destaca que os 'valores' identificados não são restritos, apontando, assim, outros significados, como simbólico, religioso, identitário, econômico, turístico, sentimental etc. O autor busca entender as diversas características simbólicas do objeto e o que este representa para a sociedade.

A ampliação do conceito de patrimônio no Brasil remonta à década de 70 , quando houve renovação e ampliação conceitual no âmbito cultural, marcada pela atuação do IPHAN. Essas conquistas demonstram-se na "Constituição da República Federativa do Brasil de 1988" (2015, p. 126) que, nos artigos 215 e 216, promoveu importantes atualizações conceituais. A substituição do termo "patrimônio histórico e artístico" por "patrimônio cultural" significa o reconhecimento da dimensão imaterial. Além disso, o texto legal explicita a proteção às manifestações populares, indígenas e afro-brasileiras, além de estabelecer instrumentos de proteção e salvaguarda, como inventários, tombamento, desapropriação, registro, entre outros (Torelly, 2012).

Nessa mesma linha, as "Recomendações de Ouro Preto/Abril-2017: Fórum de Arqueologia da SAB Acervos Arqueológicos" (Acervo da SAB, 2017) e a Nova Política do Patrimônio Cultural Material do IPHAN, Portaria n. 375, de 19 de setembro de 2018, instituem, como princípio, a indissociabilidade entre os bens culturais materiais patrimonializados e as comunidades que os têm como referência, fomentando, assim, a participação ativa da sociedade civil na elaboração de estratégias para a

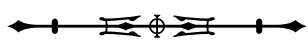


preservação do patrimônio cultural material e a gestão do patrimônio cultural em rede entre instituições, sociedade organizada e profissionais da área de preservação.

A análise das cerâmicas arqueológicas, pelo viés da ampliação do conceito de patrimônio e pelos princípios discutidos na TCR, permite que sejam identificados diversos valores destes artefatos, entre os quais destacam-se: estéticos, históricos, técnico-científicos e de utilidade. Todos estes valores são permeados por elementos culturais, sendo, assim, partes significantes na construção da identidade de um povo. Daí a contribuição desta teoria, que pressupõe que esses elementos culturais subjacentes aos valores dos objetos sejam avaliados em sua pluralidade e explicitados perante as decisões que orientarão uma intervenção - ou mesmo dirão se a intervenção é recomendada.

O valor estético das cerâmicas arqueológicas as admite como 'arte' para povos ocidentais e como 'objetos completos' para os povos ameríndios. No primeiro caso, o valor estético pode ser notado pelo estilo, pela iconografia ou pela forma da peça. Apesar de, na maioria dos casos, seguir padrões estéticos diferentes da atualidade, é reconhecido pelo rico trabalho de modelagem e de pinturas decorativas. Enquanto arte, o objeto não somente pode ser contemplado pela harmonia das suas formas, mas pelo seu valor estético, que também está presente na capacidade de agir sobre as pessoas, produzindo reações cognitivas diversas (Lagrou, 2010). Já em relação aos povos que produziram tais artefatos, eles não necessariamente partilham (ou partilhavam) da noção ocidental de arte (Lagrou, 2010). Neste caso, o valor estético, a ideia de belo, se dá pela junção de categorias de valoração, que passam pelo processo de transformação (produção) e pela sua funcionalidade, sendo esta entendida de forma dinâmica, ou seja, como a capacidade de executar “. . . atos transformativos, derivados da atividade funcional, como a panela que cozinha alimentos ou o fuso que processa o algodão. . ." (Van Velthem, 2019, p. 32).

Fica claro que não se pode entender as 'artes indígenas' da mesma forma como são compreendidas as artes em nosso mundo (Barreto, 2005), ainda que se questione o próprio conceito de arte para os povos indígenas (Lagrou, 2010). Esse valor, por vezes, combina-se ao valor histórico, pois as características formais das cerâmicas representam também aspectos da história do povo que a criou e, muitas vezes, são os únicos vestígios de culturas milenares (Bouyer, 2010). A exemplo, destaca-se a icônica urna funerária da cultura Marajoara (Figura 5), que protagonizou muitas exposições, referenciando a complexidade de formas, de representações e de organização social da Amazônia antiga. É muito valorizada pelo público ocidental devido à iconografia e à conservação que apresenta, mas carrega muitos outros significados, sobretudo simbólicos, os quais dificilmente poderemos alcançar.

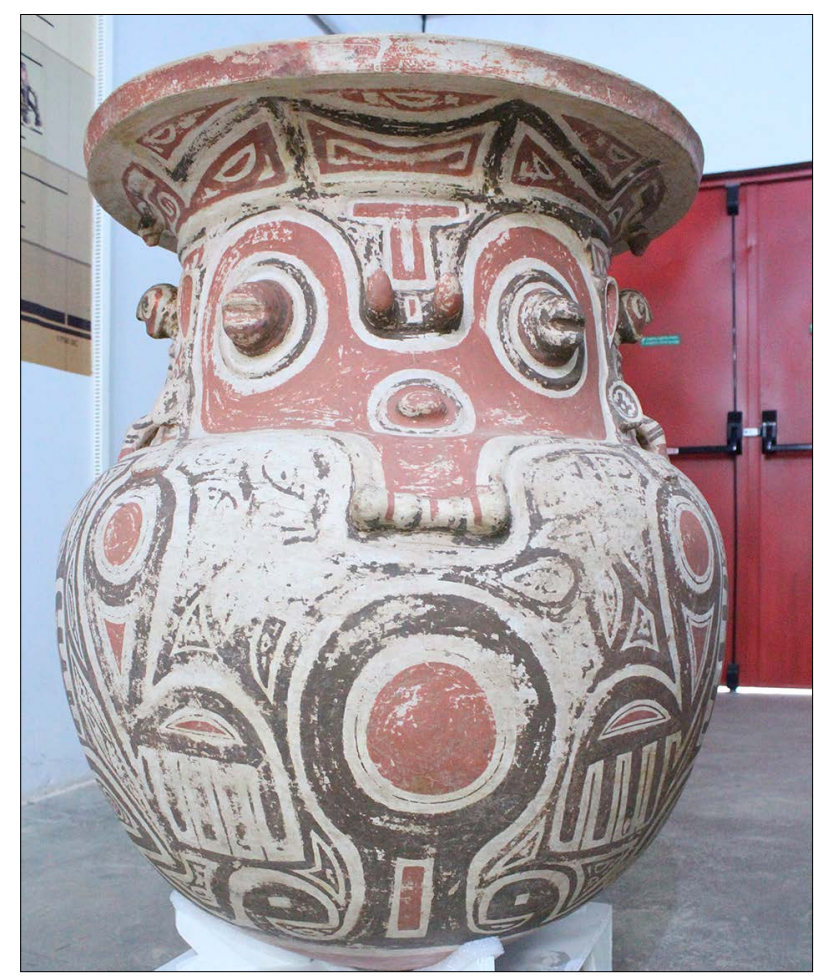

Figura 5. Urna funerária marajoara (cultura datada entre 400 e 1.400 AD) escavada pelos arqueólogos Betty Meggers e Clifford Evans, em 1949. Proveniente do sítio Guajará, um dos três tesos encontrados na localidade de Monte Carmelo, alto rio Anajás. A peça deu entrada no Museu Goeldi no mesmo ano e passou por vários processos de restauro ainda na década de 1950. Atualmente, encontra-se na Reserva Técnica Mário Ferreira Simões, MCTIC/MPEG. Foto: Lorena Porto Maia (2019).

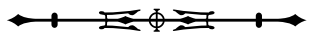


O valor técnico-científico das cerâmicas está presente nas características dos materiais utilizados na fabricação desses objetos, bem como de vestígios de outros materiais ou mesmo em marcas resultantes da sua utilização. A análise da microestrutura dessas peças permite o conhecimento acerca de diversos aspectos desses povos, como alimentação, ambiente (inclusive o tipo de solo), matérias-primas locais, entre outros. Esse conhecimento pode agregar importantes informações quanto à história desses povos, sendo também subsídio indispensável para as atividades de conservação e de restauro.

O desenvolvimento das pesquisas arqueométricas, que aplicam os conhecimentos das Ciências Exatas e da Terra no campo da Arqueologia, permite a contextualização e um conhecimento mais aprofundado sobre aspectos tecnológicos e ambientais dessas culturas antigas. Por exemplo, o estudo das características químicas e mineralógicas das cerâmicas propicia o conhecimento sobre as matériasprimas selecionadas para a fabricação das cerâmicas, seus usos, bem como a respeito do solo da época em que foram confeccionados, possibilitando a elaboração de hipóteses acerca do ambiente onde uma determinada cultura se desenvolveu. Além disso, os minerais encontrados nas amostras permitem a identificação da provável temperatura de queima das peças e a avaliação de características de performance dos objetos cerâmicos (Costa et al., 2004, 2010; Bernedo \& Latini, 2013; Natalio et al., 2015; Rodrigues et al., 2015; Rodrigues \& Costa, 2016).

O valor de utilidade, aspecto essencial das cerâmicas arqueológicas, as admite enquanto utensílio. Lembrando que, como já pontuado, para os povos originários, este valor se confunde com o próprio valor estético. As pesquisas etnoarqueológicas auxiliam na interpretação do uso de peças arqueológicas. Entre os Assurini do Xingu, por exemplo, vasilhas cerâmicas são divididas em quatro categorias gerais, ligadas ao processamento, ao consumo, ao transporte e à armazenagem de alimentos e de líquidos (Silva \& S. Lima, 2015, p. 126). O valor de uso não se limita ao ambiente doméstico. Na Amazônia, há uma enorme gama de cerâmicas produzidas e usadas em contextos cerimoniais, com alcance também para a reprodução e a reatualização de conhecimentos cosmológicos, como no caso de estatuetas e urnas funerárias (Barreto \& Oliveira, 2016). Em muitas intervenções restaurativas, é usual completar certas características de uma peça, como alças ou pescoços (Bouyer, 2010), na medida em que estas permitam aos pesquisadores e ao público leigo compreender os usos dos objetos.

Como exemplo, observa-se a estatueta antropomorfa que passou por restauro no MPEG em 2002 (Figura 6). Os fragmentos resgatados em campo são referentes ao corpo e à cabeça da peça, os quais, separadamente, têm baixos valores de uso e estético, por limitarem o entendimento ao público para o qual o restauro foi pensado, justificando, assim, a reunião das partes. Por outro lado, não se pode deixar de avaliar que ela pode ter sido fragmentada propositalmente (decapitada), conforme hipotetizado por Barreto e Oliveira (2016). A união dos fragmentos, feita por meio da reconstituição da parte que representa o pescoço, pode ser uma opção por uma determinada legibilidade do objeto, visando ao aumento dos valores de uso e estético

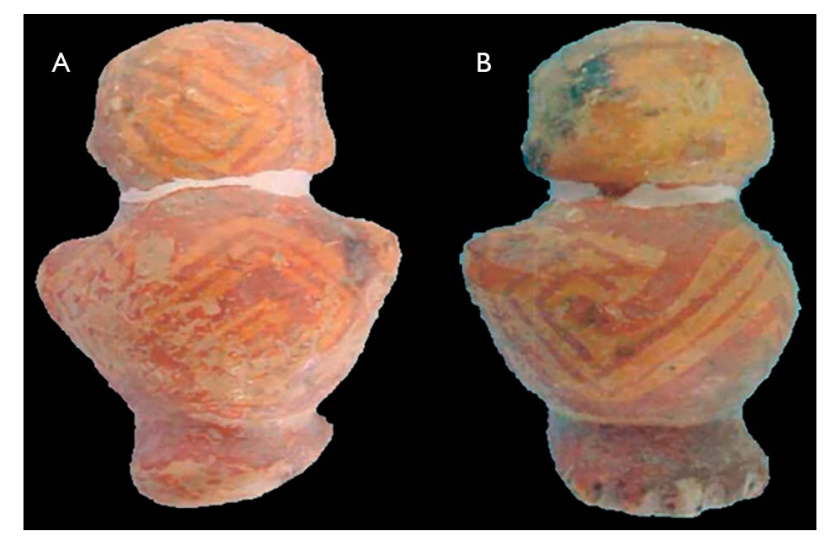

Figura 6. Estatueta antropomorfa (número de tombo D-231), cultura Marajoara. Peça do governo do estado do Pará em comodato com a Reserva Técnica Mário Ferreira Simões, MCTIC/MPEG: A) vista frontal da peça após a intervenção restaurativa; B) vista lateral da peça após a intervenção restaurativa. Restaurada em 2002. Fonte: resumo do trabalho de tratamento e conclusão das peças do governo do estado, 2002. Acervo de documentação da Reserva Técnica Mário Ferreira Simões, MCTIC/MPEG (2002).

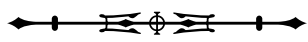


pelo público ocidental, mas isso pode não necessariamente condizer com as intenções nativas do descarte da peça.

Na maioria dos casos, artefatos cerâmicos são dotados de valor de uso, já os valores histórico e estético são relativos e dependem de outras informações referentes ao objeto. Esses valores são atribuídos por um sujeito, logo, são dotados de subjetividade (Bouyer, 2010). O reconhecimento dos significados históricos e estéticos por uma coletividade é o que orienta as mais recentes atividades de conservação e restauro, os quais objetivam principalmente a salvaguarda do significado do bem e não apenas suas características estético-formais (estilísticas).

Além disso, no caso das cerâmicas arqueológicas, é possível identificar a 'ressimbolização', amplamente discutida por Viñas (2010), ou 'ressignificação', tratada na Política do Patrimônio Cultural Material (ver Portaria n. 375, de 19 de setembro de 2018), desses artefatos. Ou seja, quando de sua criação, esses artefatos tinham um determinado uso e simbologia para seu povo (Barreto, 2010), no entanto, atualmente, estão inclusos em um contexto social totalmente novo, passando a fazer parte de coleções de museus ou acervos pessoais, assumindo, assim, novas e diversificadas significações, sejam pessoais, familiares ou coletivas (Bezerra, 2018; H. Lima, 2019). Além disso, frequentemente, a simbologia é apropriada e utilizada de forma a representar uma identidade regional ou mesmo nacional, como no caso dos desenhos marajoara que podem ser encontrados por todo o Brasil (Linhares, 2017).

Dessa forma, entre os tantos significados encontrados nas cerâmicas arqueológicas, segundo a TCR, considera-se que estes artefatos são 'objetos de restauro'. Para Viñas (2010), restaura-se os valores que este objeto representa para um grupo ou mesmo uma única pessoa e, por este motivo, é necessário que os profissionais do restauro conheçam e entendam os significados que a sociedade atribui ao objeto, para, então, interferir no bem, salvando, assim, o(s) seu(s) significado(s), e não apenas sua materialidade. Citando a museóloga Bruno (2009, pp. 14-15):
. . . a partir dos estudos desse universo da produção material é possível transgredir o seu contexto de visibilidade e penetrar nos cenários invisíveis, sensoriais e valorativos que extrapolam as barreiras impostas por análises pontuais ligadas, por exemplo, à medição dos objetos e à identificação da função dos artefatos, ou direcionadas para a organização de tipologias.

No caso de intervenções em cerâmicas arqueológicas, as atividades devem ser norteadas pelo estado em que as peças foram encontradas. Atividades como coleta e limpeza do artefato devem respeitar sujidades e marcas do tempo encontradas na superfície da cerâmica, porque podem conter importantes informações, como características do solo e interação do povo com o objeto. Atividades de conservação e restauro precisam considerar as características dos materiais empregados, de modo a evitar que estes interfiram no material original, comprometendo suas características químicas e resultando na provável perda de informações ou mesmo da própria cerâmica.

Isso significa que, em muitos casos, a conservação pode implicar a não limpeza e restauro do fragmento ou da peça, pois essas ações podem falsear ou eliminar características importantes dos artefatos. Quando a restauração for indicada para o salvamento ou mesmo para a restituição da legibilidade de uma peça, sem perda de nenhum valor significativo para o objeto, é necessário questionar-se sobre qual o estado físico ideal de preservação a ser alcançado na intervenção.

Não há um conceito unânime que determine quando se deve ou não restaurar uma cerâmica arqueológica, ou mesmo que indique qual seu estado físico ideal após a intervenção. Cada caso deve ser analisado separadamente, para que seja traçado um objetivo na intervenção que, ao optar por uma das legibilidades possíveis, como tratado por Viñas (2010), conserve a materialidade dos objetos, preservando, assim, valores e significados.

Apesar disso, muitas atividades de restauro ainda priorizam a questão formal da peça, em detrimento dos seus outros valores, resultando em restauros inadequados e que, em alguns casos, ocasionam a perda de importantes 
informações. Ademais, a utilização de materiais incompatíveis com a cerâmica acarreta a aceleração da deterioração da peça, podendo alterar as informações químicas contidas nela e até mesmo levar à perda do artefato. Em muitos casos, essas peças são os únicos vestígios materiais de um povo e, mesmo após a conservação e o restauro, continuam a ser objetos de pesquisa. Logo, essas intervenções não podem falsear as informações técnico-cientíícas contidas nesse material e que tanto têm a dizer sobre determinados processos históricos.

Estudando vasilhas cerâmicas arqueológicas dos Asurini do Xingu, Silva e S. Lima (2015, p. 125) mostram que a associação entre os campos da Conservação e da Arqueologia ampliam as possibilidades interpretativas sobre os processos de formação do registro arqueológico (uma tarefa da Arqueologia), na medida em que permitem diferenciação entre alterações provocadas pelo uso e pelos processos pós-deposicionais de biodegradação dos objetos.

Ressaltamos que nossa análise recai especificamente sobre coleções arqueológicas musealizadas, pois pensar as aplicações da TCR às coleções domésticas, tão comuns na Amazônia, é um tema patente, mas que requer outros caminhos para reflexão. Por exemplo, é comum observar intervenções feitas pelos moradores de comunidades amazônicas em peças arqueológicas, as 'caretinhas', objetivando deixá-las mais 'bonitinhas': há uma clara expressão de afeto em relação a essas peças e um intuito de aproximálas de um padrão estético local. Não raro, as peças são envernizadas ou pintadas em cores ou motivos que não compunham o objeto originalmente. Análises tangenciais a este tema constam em vários trabalhos de Arqueologia comunitária ou colaborativa na Amazônia (ver H. Lima et al., 2013, 2018; Da Rocha et al., 2014; Bezerra, 2018; Cabral, 2018).

\section{AS INTERVENÇÕES RESTAURATIVAS}

A intervenção na cerâmica arqueológica é uma atividade delicada, seja porque esse material possui muitos valores e significados que devem ser preservados, seja em função da sua condição física que, em muitos casos, é extremamente frágil. Intervir em uma cerâmica arqueológica é como mexer em um documento histórico, em um raro testemunho que permite a interpretação de culturas milenares. No entanto, a intervenção é, muitas vezes, o único meio possível de salvar este patrimônio e de o manter vivo.

As reflexões pré-restauro em cerâmicas arqueológicas são vitais para a proteção desse patrimônio. São discussões de cunho teórico-prático que consideram todos os significados da peça e sua relevância como documento histórico. Neste momento, são traçados os objetivos e os caminhos que possibilitam a conservação da materialidade e, principalmente, dos valores da peça. $\bigcirc$ processo tem paralelos com a própria pesquisa arqueológica que, ao recuperar vestígios cerâmicos do solo, busca tecer hipóteses sobre os seus possíveis significados históricos e culturais.

A intervenção arqueológica (escavação) é destrutiva por natureza (isto é, altera irremediavelmente o contexto no qual os artefatos se encontravam). A conservação arqueológica em campo propicia, neste caso, ". . . um conjunto de ações que visa minimizar a perda de informações que ocorre quando o processo de escavação separa o registro/vestígio do sítio de proveniência" (Carneiro \& S. Lima, 2008, p. 332). Os arqueólogos têm discutido, inclusive, a própria pertinência da escavação, em casos nos quais se pode oferecer a conservação in situ juntamente à produção de conhecimento.

Considerando que todo material arqueológico é rico de informações, o restauro nos artefatos cerâmicos deve buscar uma mínima intervenção visando evitar a perda de vestígios documentais e de significantes alteração das suas características físicas e químicas. Há, assim, uma aproximaç̧ão das Ciências Humanas com a Ciência da Conservação, que auxilia no momento da intervenção, buscando técnicas mais adequadas para cada caso e também no estudo da microestrutura do material (Froner, 2005).

A interdisciplinaridade permite a correlação de informações históricas com dados obtidos por meio da análise das características físicas, químicas e mineralógicas da cerâmica, possibilitando o levantamento de hipóteses acerca das culturas a elas relacionadas. $\bigcirc$ auxilio de outras áreas do conhecimento 
proporciona o desenvolvimento de técnicas que considerem o comportamento do material cerâmico arqueológico e suas reações com produtos de restauro, buscando, desta forma, caminhos que respeitem a longevidade da peça e que resultem na preservação e na salvaguarda deste patrimônio para as próximas gerações (Froner, 2005, 2016).

As cerâmicas arqueológicas são normalmente não vidradas e formadas a partir de queimas a baixas temperaturas, apresentando textura macia, porosa e quebradiça, principalmente quando úmidas. Apesar da aparente estabilidade, estão sujeitas à deterioração por fatores ambientais (físicos, químicos e biológicos) e humanos (S. Lima, 2002). A intervenção nesses artefatos acontece em quatro etapas: coleta, limpeza, conservação e restauro.

Como vimos, a coleta é a primeira fase da intervenção, sendo o momento em que a peça sai do ambiente no qual estava há centenas ou milhares de anos - e onde, normalmente, já alcançou a estabilidade - para outro local totalmente novo, com condições de umidade, pressão e temperatura diferentes. Ademais, quando essas cerâmicas são encontradas, estão, na grande maioria dos casos, fragmentadas e frágeis, precisando, assim, de uma coleta extremamente delicada, a fim de não causar ainda mais danos ou perda de fragmentos. Por esse motivo, frequentemente, necessitam de consolidação em campo, para que possam ser transportadas até o laboratório ou a reserva técnica adequada. Há pesquisas nesta área que discutem e indicam técnicas e produtos que devem ser utilizados para a coleta adequada da cerâmica arqueológica e sua conservação em campo (Lorêdo, 1994; Rye, 2007).

A limpeza pode ser considerada como a segunda fase da intervenção, a qual é um processo complexo e irreversível. Os procedimentos realizados podem ser mecânicos ou químicos e ambos são fundamentais para a posterior análise do material arqueológico, porque podem alterar suas características ou levar à perda de alguma informação. Logo, são procedimentos delicados e que demandam um estudo prévio, devendo ser executados prioritariamente em laboratórios. Para as limpezas realizadas em campo, aconselha-se o uso de laboratório móvel, que permita condições adequadas para o tratamento prévio da peça coletada.

A higienização da peça pode ser entendida como uma microescavação na qual se estuda e documenta todas as camadas, antes que sejam removidas. Neste momento, observa-se a textura, a dureza e a adesão das camadas, além da coleta de amostras para posteriores análises laboratoriais. Durante esta investigação, avalia-se a possibilidade de remoção das camadas sobre o objeto. O que determina a manutenção dessas camadas é a sua importância documental e a possibilidade de causarem dano ou perda do artefato após a sua remoção. Os parâmetros de limpeza também estão atrelados ao objetivo da pesquisa da qual as peças fazem parte e ao tipo de informação que se almeja encontrar. Esses dados interferem no grau de limpeza e nos procedimentos adotados durante esta etapa (S. Lima, 2016).

Como exemplo de uma peça que passou por um processo de higienização, observa-se uma urna funerária da cultura Aristé (Figura 7). Nesta limpeza, realizada em 2000, no âmbito da exposição "Unknown Amazon", foi

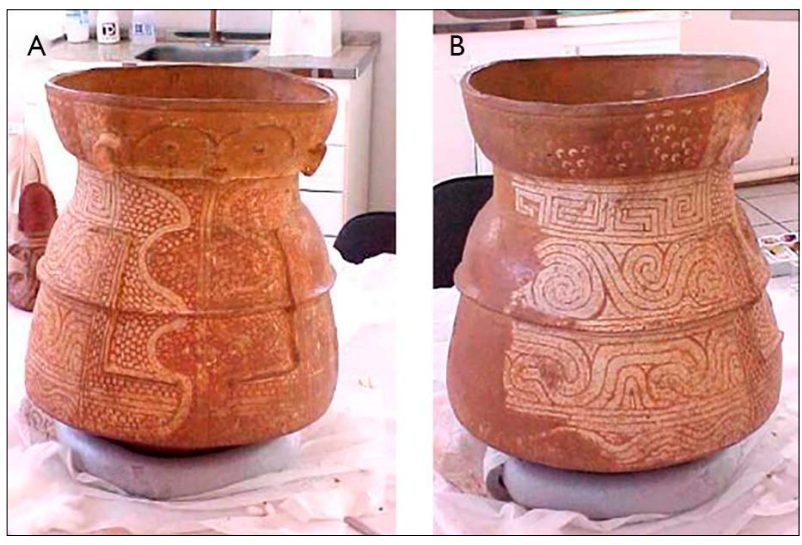

Figura 7. Urna funerária (número de tombo T-243) da cultura Aristé durante o processo de limpeza realizada em 2000 em função da participação da peça na exposição "Unknown Amazon", no British Museum, Inglaterra, em 2001. A) Vista frontal da peça; B) vista posterior da peça. Urna da Reserva Técnica Mário Ferreira Simões, MCTIC/MPEG. Procedência: Monte Curú, rio Cunani, Amapá. Coletores: Emílio Goeldi e Aureliano Guedes, 1895. Restauradora: Silvia Cunha Lima. Fotos: Cristiana Barreto (2000).

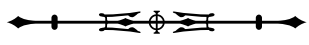


retirada uma camada de material que estava fixa nas laterais externas, provavelmente referente ao solo em que o objeto estava enterrado, revelando, assim, a decoração rica em desenhos e pinturas aplicados no corpo da urna. No processo, foi decidido manter intacta uma parte da cerâmica, a fim de salvaguardar o aspecto que tinha quando foi encontrada (Freitas \& Braga, n.d.) (Figura 8).

A conservação deve estar presente tanto nas atividades em campo, como no pós-campo em laboratórios, reservas técnicas e exposições. É responsável por estabilizar a cerâmica e mantê-la em condições ideais para a salvaguarda do bem. Entre as medidas de conservação realizadas em campo, destaca-se a consolidação, essencial para a proteção de peças mais frágeis e suscetíveis a fragmentação ou perda de parte do material. A consolidação dessas cerâmicas permite melhor documentação e manuseio, contribuindo para o estudo do material arqueológico e da cultura da qual faz parte (Jones-Amin, 2014).

Quantoaos produtos utilizados na intervenção, indica-se que devem ser anteriormente testados, de modo a analisar sua interação e interferência no material cerâmico. Sabendo-se que, em prática, não há material totalmente reversível,

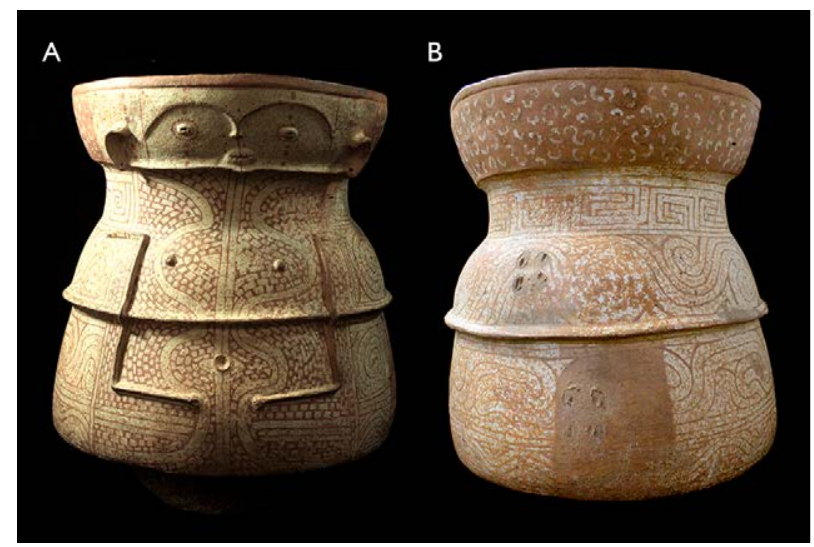

Figura 8. Urna funerária (número de tombo T-243) da cultura Aristé, em condições atuais. Peça da Reserva Técnica Mário Ferreira Simões, MCTIC/MPEG. Procedência: Monte Curú, rio Cunani, Amapá. Coletores: Emílio Goeldi e Aureliano Guedes, 1895. A) Vista frontal da urna, onde é possível perceber os detalhes de pintura e modelagem revelados após a limpeza; B) vista posterior da urna, onde se pode identificar a área na qual não foi realizada a higienização. Fotos: Lorena Porto Maia (2019). deve-se, portanto, ponderar qual material e qual técnica é mais compatível para cada caso, com o objetivo de encontrar uma atividade com maior grau de reversibilidade (Viñas, 2010).

Partindo dessas premissas, é possível determinar quais procedimentos são mais adequados para o caso determinado. $\bigcirc$ conceito de 'reversibilidade' étratado desde as teorias clássicas, principalmente pela teoria do restauro de Brandi. No entanto, Viñas (2010) traz, na sua obra, uma nova abordagem, ao explicar que a 'reversibilidade' é melhor aplicada se medida em graus de acordo com cada caso, uma vez que não existem materiais totalmente reversíveis e nem totalmente irreversíveis. Em paralelo a este conceito, Viñas (2010) aborda a 'retratabilidade' do objeto, ou seja, a possibilidade de remover os materiais previamente aplicados, assemelhando-se, assim, ao antigo entendimento do conceito de 'reversibilidade'.

Ao traçar os objetivos da intervenção, é importante ter em mente também a legibilidade da peça. Todo artefato transmite uma mensagem que está relacionada não apenas com a intenção inicial do artesão, mas também com o estado em que o objeto se encontra. Quando se restaura, escolhe-se uma das legibilidades, em detrimento de outras, e esta escolha deve estar relacionada não apenas aos estudos anteriores acerca da história do artefato, mas também com os valores e os significados contemporâneos a ele.

A escolha de uma das legibilidades da peça também está presente na etapa de limpeza, pois a retirada das camadas superficiais de impurezas e de resquícios do solo é uma atividade irreversível e que promove a mudança do aspecto do objeto. Ou seja, a legibilidade escolhida neste caso, como no exemplo da urna funerária da cultura Aristé (Figura 6), é a da peça 'limpa', sem as camadas superficiais presentes após a coleta.

No momento desta restituição da imagem, é importante também que o restaurador não crie novos elementos. Ou seja, é necessário estudar a fundo cada caso e, assim, avaliar a quantidade de informações acerca do objeto, que podem ser desde os fragmentos encontrados até estudos históricos, para somente, então, propor a reconstituição das áreas de lacuna. No caso de

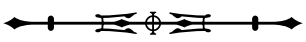


peças em que há mais lacunas do que fragmentos, não é aconselhável a remontagem, sendo mais significativa a salvaguarda dos próprios fragmentos.

Podem ser encontradas algumas intervenções nesse sentido, como a realizada na urna antropomorfa da cultura Santarém (Figura 9). Os fragmentos foram coletados em sítio arqueológico e, em 2000, foi realizado o restauro, que consistiu na colagem dos fragmentos encontrados e na reconstituição das áreas de lacuna. Ressalta-se, neste caso, que se obtinha apenas um pequeno fragmento do objeto original modelado sobre a figura humana (Figura 9B) e que, durante a intervenção, este objeto foi modelado em um formato de vasilha. Percebe-se que o produto utilizado para restauro é diferente do material cerâmico original, permitindo, assim, a identificação do que é novo e do que é antigo. Além disso, a vasilha modelada tem formato simplificado e diferente da olaria da cultura Santarém, cujas peças são muito ricas em decorações e apêndices. Esse aspecto foi também importante para facilitar a identificação da parte nova e da antiga.

Destacam-se dois padrões de restauro em objetos arqueológicos: o arqueológico e o de museu. $\bigcirc$ primeiro é facilmente identificado e classificado, pois não pretende

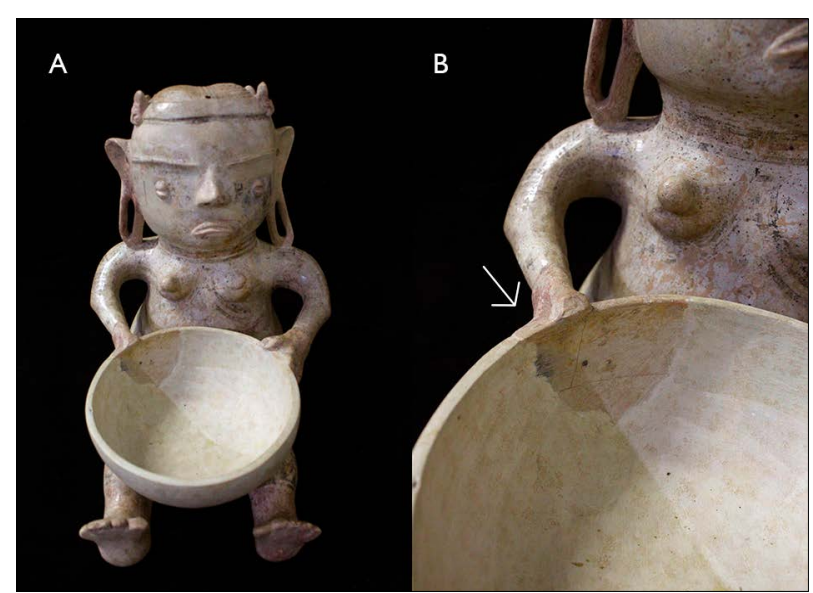

Figura 9. Estatueta antropomorfa (número de tombo T-516) da cultura Santarém. Peça da Reserva Técnica Mário Ferreira Simões, MCTIC/MPEG. Coletor: Frederico Barata. Restaurada em 2000, em função da participação da peça na exposição "Unknown Amazon", realizada no British Museum, Inglaterra, em 2001. A) Vista frontal da peça na condição atual; B) detalhe do material original do vaso restaurado sobre a estatueta. Foto: Lorena Porto Maia (2019). sugerir que o objeto está completo ou intacto. O fragmento é amplamente aceito e, quando há a remontagem dos pedaços, as emendas são visíveis, identificando-se o estado em que a peça foi resgatada. Resultam, assim, em restauros 'reconhecíveis', 'visíveis' ou perceptíveis. O segundo é conhecido como restauro ilusionista, que busca restituir a imagem da peça de forma harmônica e discreta, minimizando a identificação da área restaurada. Este tipo de intervenção remonta aos primórdios do interesse por antiguidades, quando os vasos só eram valorizados se estivessem completos (Bouyer, 2010).

Em geral, os museus priorizam, em suas exposições, peças inteiras e restauradas em relação aos fragmentos, em razão de possuírem maior capacidade de transmitir, por meio de sua forma e estética, a mensagem ao visitante. Porém, há fragmentos que não têm capacidade de reconstituição da legibilidade da peça e, em função da sua importante procedência, são expostos, a fim de representar um determinado período, povo e cultura.

Quanto à metodologia de intervenção restaurativa em peças de exposição, apesar de cada caso de restauro precisar ser analisado separadamente, quando se tratam de coleções de museus, observa-se a opção por homogeneidade nas intervenções de peças de uma mesma coleção (Bouyer, 2010). Este foi o caso da exposição "Unknown Amazon". As peças selecionadas para o evento apresentavam grande diversidade de estado de conservação, por esse motivo foi desenvolvido um workshop de conservação e restauro que, além de capacitar os profissionais, possibilitou a homogeneização no tratamento de conservação e restauro do acervo (Braga \& Queiroz, 2000).

No caso do Museu Goeldi, apesar do rico e extenso acervo e de serem encontradas muitas peças que passaram por processos de conservação e restauro, não há documentação dessas atividades. Durante o desenvolvimento da presente pesquisa, foi possível elencar os tipos de restauro encontrados nessa reserva, os quais, em seguida, foram caracterizados e descritos segundo a intenção final do restaurador. Ressalta-se que essa classificação não segue restritamente uma ordem

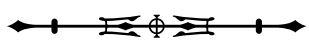


cronológica, podendo, portanto, ser encontrados dois ou mais tipos em um mesmo período. Os tipos de restauro encontrados podem ser classificados da seguinte forma: 1) reconstituição de volume; 2) reconstituição de volume com aproximação da tonalidade original; 3) reconstituição de volume, decoração e pintura. Não há necessariamente uma lógica cronológica entre esses tipos.

No restauro de 'reconstituição de volume', a intenção do restaurador é de reconstituição apenas do volume da peça e o produto de intervenção utilizado permanece na tonalidade natural. Não se encontra nenhum tipo de pintura sobre a área restaurada, resultando em um restauro visível, próximo ao descrito no 'restauro arqueológico', tratado por Bouyer (2010). Exemplificativamente, observam-se, na Figura 10, quatro peças do acervo do MPEG que

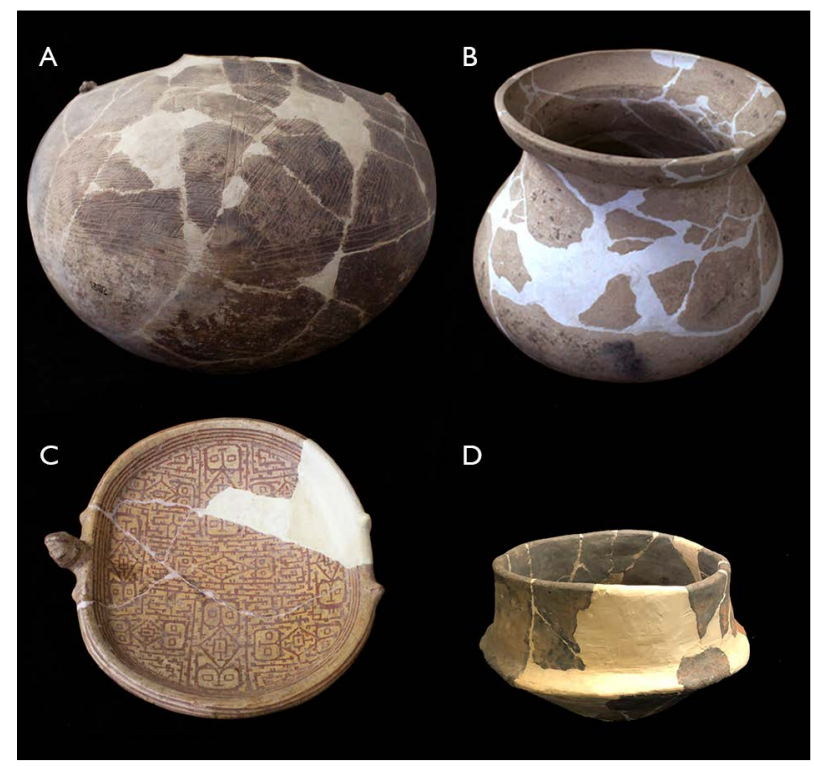

Figura 10. Peças do acervo da Reserva Técnica Mário Ferreira Simões, MCTIC/MPEG, que passaram por intervenções de conservação e restauro. A) Vaso cerâmico (número de tombo T-2589), procedente do rio Urubu - AM-IT-26, coletado por Mário Simões e equipe em 1970, restaurada na década de 1980; B) vaso cerâmico (número de tombo T-1978) procedente do lago de Silves - AM-IT-7, coletado por Mário Simões e equipe em 1970, restaurada na década de 1980; C) prato cerâmico da cultura Marajoara procedente dos arredores da fazenda Tapera, ilha do Marajó, comodante: governo do estado do Pará, restaurada na década de 1980; D) vaso cerâmico (número de tombo T-2862) procedente da ilha do Marajó e coletada por Denise Schaan em 1998. Fotos: Lorena Porto Maia (2019). passaram por intervenção de conservação e restauro, nas quais os fragmentos foram colados e suas áreas de lacuna, preenchidas. Após a intervenção, é possível identificar claramente a união dos fragmentos e o material novo de restauro na cor branca.

Na Figura 11, observa-se uma outra técnica de restauro, mas com a mesma intenção. No interior da urna, observa-se a utilização de um tipo de papel e cola para a consolidação da peça, além disso, a borda e a parte do corpo foram reconstituídas. Assim como nos exemplos anteriores, os materiais de restauro permaneceram na tonalidade e textura originais, sendo facilmente perceptíveis. Destaca-se também que, nesses casos, não há reconstituição de decoração.

No restauro de 'reconstituição de volume com aproximação da tonalidade original', a intenção do restaurador é de preencher a volumetria das áreas de

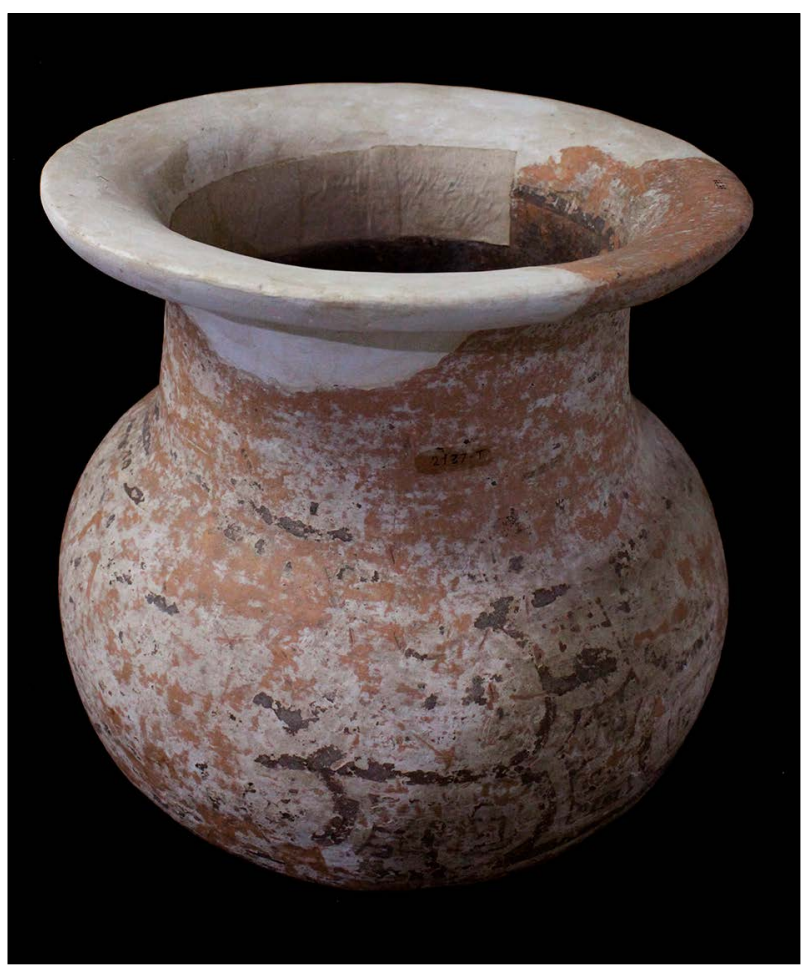

Figura 11. Urna funerária da cultura Marajoara. Peça da Reserva Técnica Mário Ferreira Simões, MCTIC/MPEG. Procedência: rio Camutins, fazenda São Marcos, ilha do Marajó. Comodante: governo do estado do Pará. Data do restauro não identificada. Foto: Lorena Porto Maia (2019)

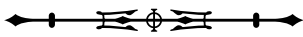


lacunas, assim como no caso anterior. No entanto, são utilizados pigmentos para aproximar o tom do material utilizado para a prótese com o da cerâmica original. Nesta opção, ainda é possível diferenciar a área de restauro do material original, mas a mudança é mais discreta, se comparada com o primeiro tipo de restauro (Figura 12).

$\mathrm{Na}$ Figura 13, observa-se uma técnica de restauro em que, provavelmente, foi utilizada uma espécie de papel com cola para a consolidação dos fragmentos e preenchimento das áreas de lacuna. Observa-se que, assim como no caso anterior, o material utilizado para restauro foi também pigmentado, atingindo uma tonalidade aproximada à da cerâmica original.
No restauro classificado como 'reconstituição do volume, decoração e pintura', além da reconstituição da lacuna volumétrica, há também a aproximação da tonalidade da cerâmica original e, além disso, é realizada a reconstituição da decoração e da pintura, por meio da técnica de pontilhismo. Dessa forma, a intervenção tem como intuito reconstituir por completo a imagem da peça e, ao mesmo tempo, minimizar o impacto visual do restauro, o qual pode ser comparado ao 'restauro de museu', ou 'ilusionista', tratado por Bouyer (2010). $\mathrm{Na}$ Figura 14, observam-se quatro exemplares de peças do acervo do MPEG, restauradas no ano 2000 para participação na exposição "Unknown Amazon" (2001).

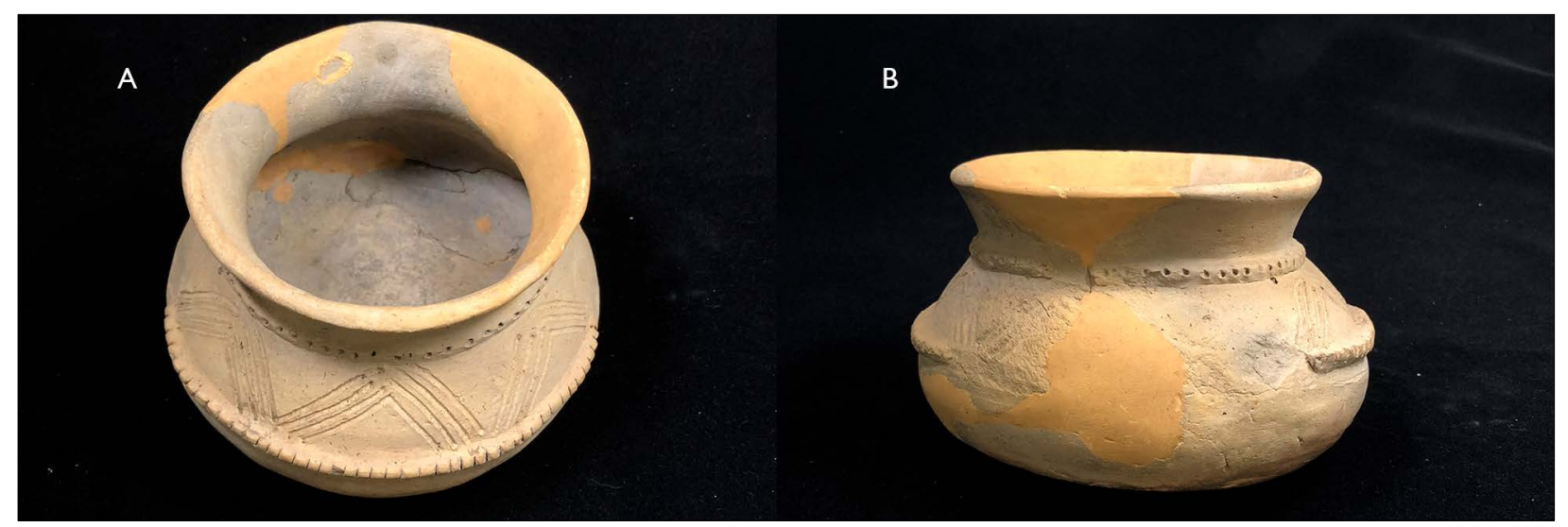

Figura 12. Vaso cerâmico (número de tombo T-1014) procedente de Santarém, coleção Townsend. Peça da Reserva Técnica Mário Ferreira Simões, MCTIC/MPEG. A) Vista superior; B) vista lateral. Data do restauro não identificada. Fotos: Lorena Porto Maia (2019).
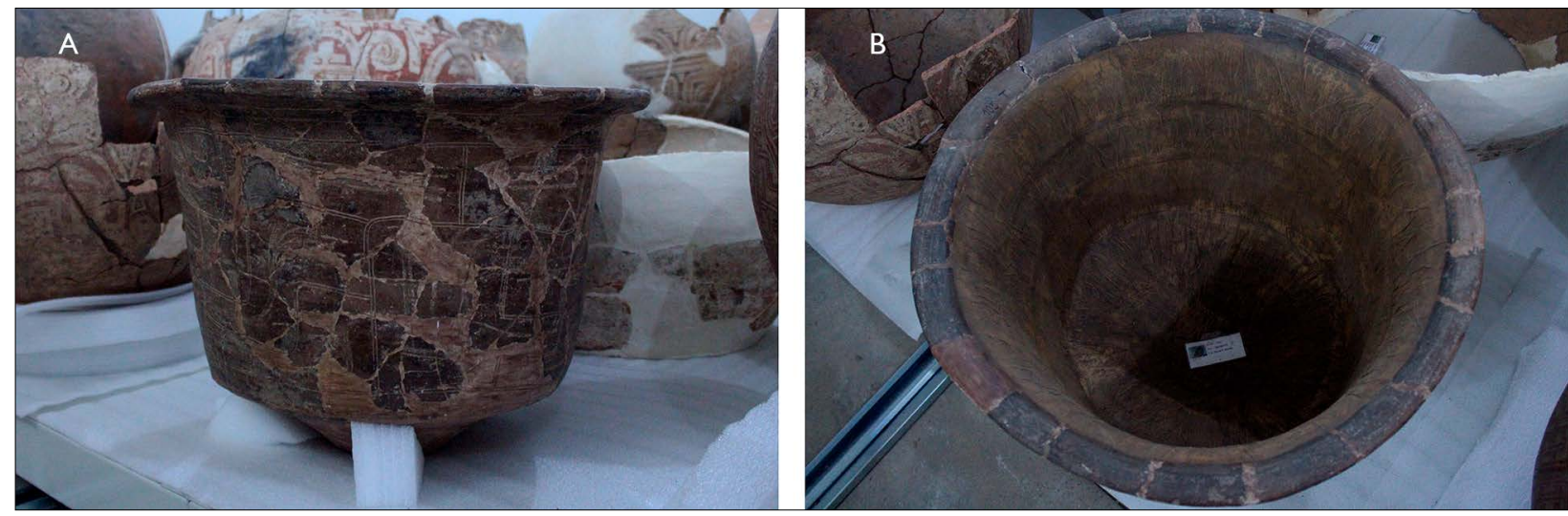

Figura 13. Vaso cerâmico (número de tombo T-105) da cultura Marajoara, procedente da ilha do Marajó. Coletado por Mário Simões. Peça da Reserva Técnica Mário Ferreira Simões, MCTIC/MPEG. Data do restauro não identificada. Fotos: Lorena Porto Maia (2019).

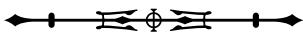




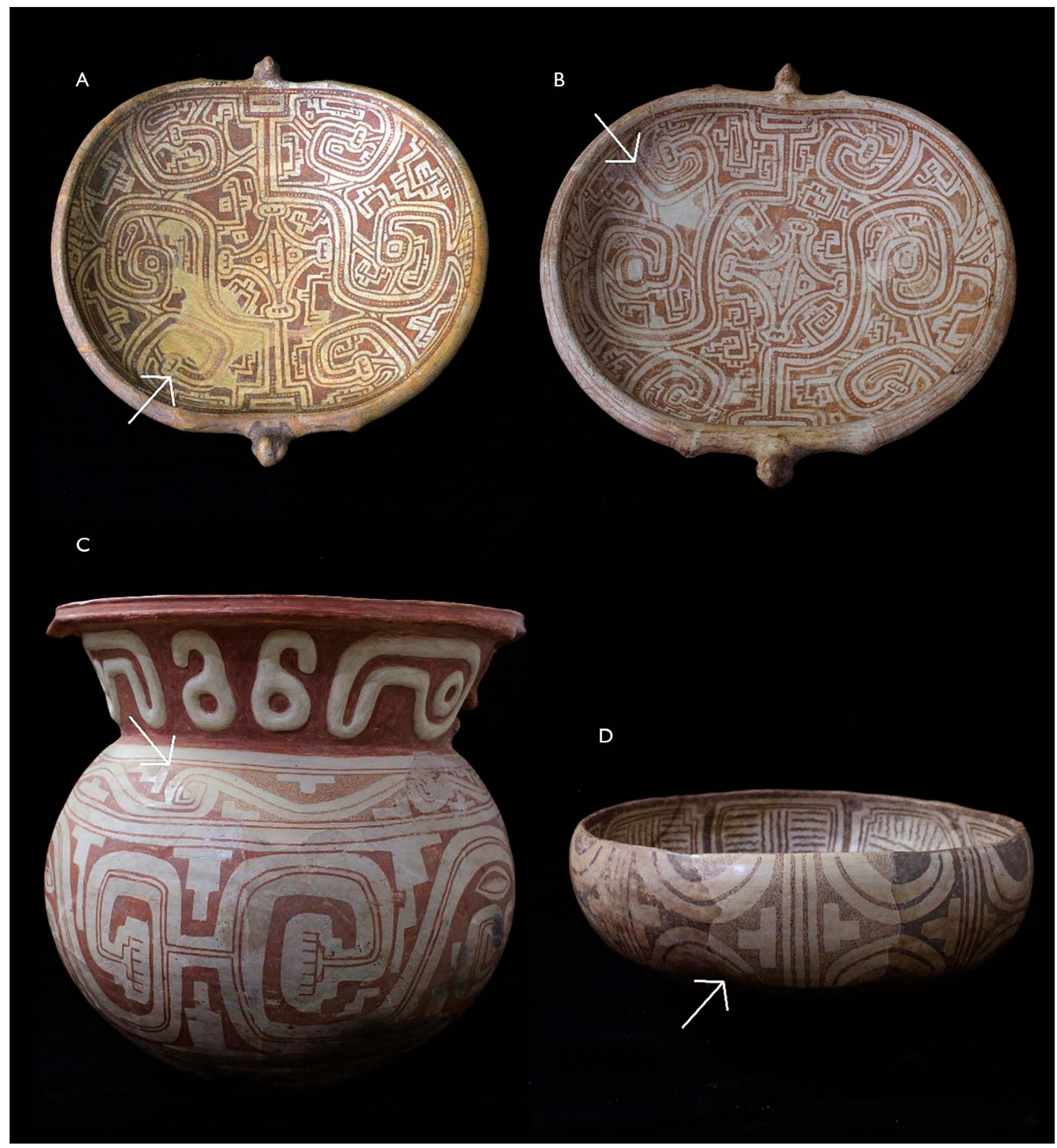

Figura 14. Peças do acervo da Reserva Técnica Mário Ferreira Simões, MCTIC/MPEG, que passaram por intervenções de conservação e restauro. A) Prato cerâmico da cultura Marajoara (número de identificação GE30), procedente do rio Camutins, ilha do Marajó, comodato do governo do estado do Pará; B) prato cerâmico da cultura Marajoara (número de identificação GE273), procedente do rio Camutins, ilha do Marajó, comodato do governo do estado do Pará; C) urna funerária antropomorfa da cultura Marajoara (número de tombo 1598), procedente do rio Camutins, ilha do Marajó, coletada por Meggers e Evans em 1949, restaurada em 2000 para a exposição "Unknow Amazon"; D) tigela cerâmica (número de tombo T-97) da cultura Marajoara, procedente da ilha do Marajó, restaurada em 2000 para a exposição "Unknow Amazon". Fotos: Lorena Porto Maia (2019).

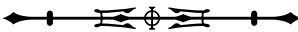


Ressalta-se que muitas peças observadas na reserva técnica do Museu Goeldi e que possuem intervenções restaurativas já apresentam patologias ${ }^{4}$ na zona de interface ou mesmo na quase totalidade da peça. Pode-se observar, por exemplo, o prato cerâmico da coleção Curt Nimuendajú (Figura 15) que apresenta restauro anterior, sem data documentada, com alteração na cor do material introduzido e sua superfície de contato com o material antigo.

O que caracteriza a conservação e o restauro da cerâmica arqueológica não são as técnicas e os instrumentos utilizados, mas sim a intenção desta intervenção. $O$ restauro não se resume ao que é feito, mas para o que ou para quem é feito. Preservam-se, assim, os valores desse patrimônio e a sua importância simbólica para a sociedade, e não apenas aspectos formais e materiais (Viñas, 2010).

Considerando as referidas premissas, destacam-se três diferentes intenções na intervenção em uma cerâmica arqueológica que objetivam melhorar a conservação, a compreensão e a aparência. A primeira pretende agir em direção à garantia da manutenção e à salvaguarda das peças ou dos fragmentos. Entre as atividades destacadas nesta intervenção, estão a remontagem de fragmentos, o preenchimento de lacunas e de fissuras ou fraturas, principalmente em áreas estruturalmente significantes. A segunda pretende atingir um resultado final que permita que o espectador entenda a função, a forma e a decoração da peça. Entende-se que este tipo de restauro esteja próximo do 'restauro de museu' e que, na sua execução, esteja o preenchimento não apenas do volume, mas também da modelagem e da pintura. Por último, a intenção de melhorar a aparência está diretamente relacionada a questões estéticas da peça. Assim como no restauro anterior, é aceitável a reconstituição de volume e de decorações, mas o objetivo é aumentar o valor estético do objeto, em detrimento dos outros (Bouyer, 2010). Essas três premissas não são mutuamente excludentes e tampouco compreendem uma

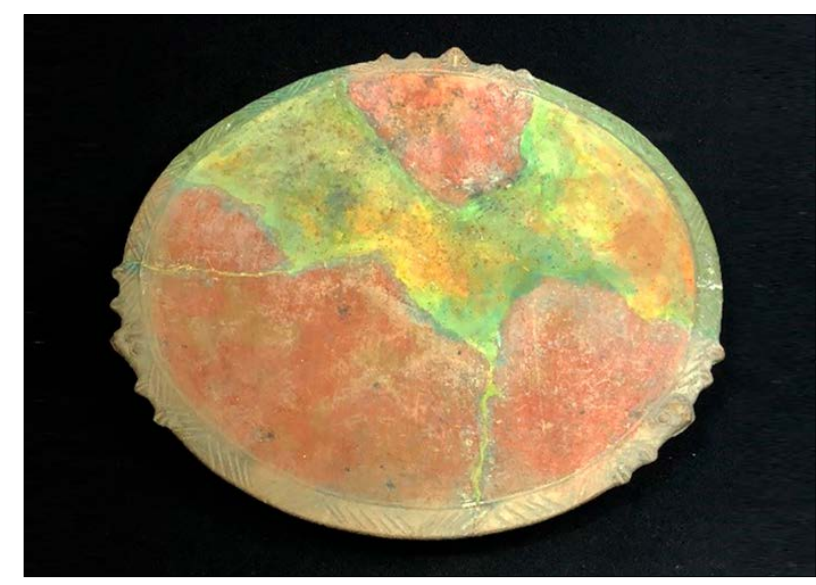

Figura 15. Prato cerâmico (número de tombo T-331) da coleção Curt Nimuendajú. Peça da Reserva Técnica Mário Ferreira Simões, MCTIC/MPEG. Data de restauro não identificada. Foto: Lorena Porto Maia (2019).

única legibilidade possível. Cabe ao restaurador, em conjunto com a equipe curatorial, definir e explicitar tais escolhas.

\section{CONCLUSÕES}

A pesquisa identificou diferentes tipos de restauro aplicados ao longo do tempo nas cerâmicas arqueológicas do Museu Goeldi, os quais são reflexos da mudança do pensamento intervencionista na região amazônica quanto ao estado pós-intervenção ideal dessas peças. Os restauros variam quanto à intenção do restaurador, às técnicas e aos tipos de materiais utilizados, resultando em reconstituições que se diferenciam quanto ao preenchimento de lacunas volumétricas, decoração e pintura.

Quanto à aplicação das teorias de restauro para intervenção em cerâmicas arqueológicas, considera-se que a TCR é a mais adequada atualmente para esse acervo, em função da abrangência na atuação da preservação do patrimônio. Assim, a intervenção não é orientada apenas pelas questões morfológicas do objeto, mas também por todos os seus outros valores intrínsecos (documental, técnico-científico, histórico, de utilidade e subjetivo).

\footnotetext{
4 Alterações no material original causadas por fatores físicos, químicos ou biológicos que aceleram o processo de deterioração do patrimônio, podendo causar a perda de parte ou de todo o objeto.
} 
A gestão do acervo de cerâmicas arqueológicas deve contar com a participação ativa não apenas de uma equipe profissional multidisciplinar (museólogos, arqueólogos e conservadores), mas também da própria sociedade. Nesse sentido, as atividades de conservação e de restauro devem atuar na manutenção e, quando necessário, na recuperação da memória representada por esse acervo, de modo a manter viva sua importância e seu significado para a identidade cultural brasileira.

A preservação dos valores intrínsecos à cerâmica arqueológica durante as intervenções restaurativas permite a salvaguarda do bem cultural na sua total potencialidade de informaç̧ões. No entanto, sabendo que cada caso deve ser analisado separadamente, não há uma única forma de intervenção no artefato cerâmico. Cabe ao profissional de restauro analisar o estado em que a peça foi encontrada e a intensidade de cada um de seus valores, para que possa traçar o melhor plano de intervenção e salvaguarda deste patrimônio cultural material.

\section{AGRADECIMENTOS}

Agradecemos à Coordenação de Aperfeiçoamento de Pessoal de Nível Superior (CAPES), pela bolsa de pesquisa concedida à primeira autora, e ao Conselho Nacional de Desenvolvimento Científico e Tecnológico (CNPq), pela bolsa de produtividade em pesquisa concedida à segunda autora. Ao Programa de Pós-Graduação em Arquitetura e Urbanismo da Universidade Federal do Pará (UFPA), ao MPEG e ao Laboratório de Conservação, Restauração e Reabilitação (LACORE), por auxiliarem e favorecerem o desenvolvimento da pesquisa.

\section{REFERÊNCIAS}

Acervo da SAB. (2017). Recomendações de ouro Preto/Abril-2017: Fórum de Arqueologia da SAB - Acervos Arqueológicos. Revista Arqueologia Pública, 11(2), 2-5.

Araújo, L. M. (2019a). Lista de Exposições com Artefatos Marajoaras Arqueologia e Arquivo MPEG. Belém. [Documento não publicado cedido pelo autor, para uso interno. Curadoria da Reserva Técnica Mário Ferreira Simões/Museu Paraense Emílio Goeldi].
Araújo, L. M. (2019b). Listagem final de exposições levantadas nos arquivos da Reserva Técnica de Arqueologia Mário Ferreira Simões, no Arquivo Guilherme De La Penha e na Biblioteca Domingos Soares Ferreira Penna. Belém. [Documento não publicado cedido pelo autor, para uso interno. Curadoria da Reserva Técnica Mário Ferreira Simões/Museu Paraense Emílio Goeldi].

Barreto, C. (2005). Arte e arqueologia na Amazônia antiga. In Working Paper (pp. 66-65). Oxford: Centre for Brazilian Studies. Recuperado de https://www.lac.ox.ac.uk/sites/default/ files/lac/documents/media/cristiana20barreto2066.pdf

Barreto, C. (2010). Cerâmica e complexidade social na Amazônia antiga: uma perspectiva a partir de Marajó. In E. Pereira \& V. Guapindaia (Orgs.), Arqueologia Amazônica (pp. 193-212). Belém: Museu Paraense Emílio Goeldi.

Barreto, C., \& Oliveira, E. (2016). Para além de potes e panelas: cerâmica e ritual na Amazônia antiga. Habitus, 14(1), 51-72. doi: http://dx.doi.org/10.18224/hab.v14.1.2016.51-72

Bernedo, A. V. B., \& Latini, R. M. (2013). Cerâmicas arqueológicas brasileiras: uma revisão de estudos arqueométricos em sítios arqueológicos do Acre, bacia amazônica e da Região dos Lagos, Rio de Janeiro. Geochimica Brasiliensis, 27(2), 140-151.

Bezerra, M. (2011). "As moedas dos índios": um estudo de caso sobre os significados do patrimônio arqueológico para os moradores da Vila de Joanes, ilha de Marajó, Brasil. Boletim do Museu Paraense Emílio Goeldi. Ciências Humanas, 6(1), 57 70. doi: http://dx.doi.org/10.1590/S1981-81222011000100005

Bezerra, M. (2018). Com os cacos no bolso: o colecionamento de artefatos arqueológicos na Amazônia brasileira. Revista do Patrimônio Histórico e Artístico Nacional, 38, 85-99.

Boito, C. (2008). Os restauradores (3 ed.) (Artes e Ofícios). São Paulo: Ateliê Editorial.

Bouyer, È. (2010). Quelques pistes de réflexion sur la restauration perceptible des vases céramiques antique. Conservation, Exposition, Restauration d'Objets d'Arts. doi: https://doi. org/10.4000/ceroart.1618

Braga, G. B. (2004). Arqueologia e arte contemporânea-visões paralelas. Revista do Museu de Arqueologia e Etnologia, (14), 361-364. doi: https://doi.org/10.11606/issn.2448-1750. revmae.2004.89695

Braga, G. B. (2006). Teoria da Restauração de Brandi: uma abordagem para objetos artísticos, arqueológicos e etnográficos. Revista do Museu de Arqueologia e Etnologia, (15-16), 337-346. doi: https://doi.org/10.11606/issn.2448-1750.revmae.2006.89725

Braga, G. B., \& Queiroz, M. N. (2000). Conservação e restauro de cerâmicas arqueológicas: workshop. Revista do Museu de Arqueologia e Etnologia, (10), 323-327. doi: https://doi. org/10.11606/issn.2448-1750.revmae.2000.109396 
Brandi, C. (2013). Teoria da restauração (4 ed.). (Artes e Ofícios). São Paulo: Ateliê Editorial.

Bruno, M. C. O. (2009). Estudos de cultura material e coleções museológicas: avanços, retrocessos e desafios. In M. Granato \& M. F. Rangel (Orgs.), Cultura material e patrimônio da Ciência e Tecnologia (pp. 14-25). Rio de Janeiro: MAST.

Constituição da República Federativa do Brasil de 1988. (2015). Brasilia: Senado Federal, Coordenações de Edições Técnicas. Recuperado de https://www2.senado.leg.br/bdsf/bitstream/ handle/id/508200/CF88 EC85.pd? sequence=1\&isAllowed=y

Cabral, M. P. (2018). Entre passado e presente: arqueologia e coletivos humanos na Amazônia. Revista Teoria \& Sociedade, 24(2).

Carneiro, C. G., \& Lima, S. C. (2008). Experiências em conservação e educação patrimonial no contexto de escavações arqueológicas. Revista do Museu de Arqueologia e Etnologia, (18), 331-335. doi: https://doi.org/10.11606/issn.2448-1750.revmae.2008.89861

Costa, M. L., Carmo, M. S., Oliveira, E. C., Lima, H., Kern, D. C., \& Goeske, J. (2010). Mineralogia e composição química de fragmentos de cerâmicas arqueológicas em sítios de terra preta de índio. In W. G. Teixeira, D. C. Kern, B. E. Madari, H. N. Lima \& W. Woods (Orgs.), As terras pretas de índio da Amazônia: sua caracterização e uso deste conhecimento na criação de novas áreas (1 ed., Vol. 1, pp. 225-241). Manaus: Embrapa Amazônia Ocidental.

Costa, M. L., Kern, D. C., Pinto, A. H. E., \& Souza, J. R. T. (2004). The ceramic artifacts in archaeological black earth (terra preta) from Lower Amazon region, Brazil: chemistry and geochemical evolution. Acta Amazonica, 34(3), 375-386. doi: https://doi. org/10.1590/S0044-59672004000300004

Da Rocha, B. C., Beletti, J., Py-Daniel, A. R., Moraes, C. P., \& Oliveira, V. H. (2014). Na margem e à margem: arqueologia amazônica em territórios tradicionalmente ocupados. Amazônica: Revista de Antropologia, 6(2), 358-384. doi: http://dx.doi.org/10.18542/ amazonica.v6i2.1873

Dos Santos, R. T. (2010). Trabalho de restauração e conservação dos artefatos marajoaras da coleção Dita Acatauassu - IPHAN. Belém. [Relatório para uso interno. Curadoria da Reserva Técnica Mário Ferreira Simões/Museu Paraense Emílio Goeldi].

Freitas, Â. M., \& Braga, G. B. (n.d.). Relatório de restauração de peças arqueológicas do Museu Paraense Emílio Goeldi (Projeto "Unknown Amazon"-British Museum). Relatório para uso interno. Belém. [Curadoria da Reserva Técnica Mário Ferreira Simões/Museu Paraense Emílio Goeldi].

Froner, Y.-A. (2005). Ciência da conservação ou conservação científica? Hipóteses para uma reflexão. [Festival de Arte]. Departamento de Artes Visuais. Faculdade de artes, Filosofia e Ciências Sociais. Universidade Federal de Uberlândia, Uberlândia, Minas Gerais.
Froner, Y.-A. (2016). Demandas históricas: a constituição da ciência da conservação e a formação do conservador-restaurador. Conservar Património, (23), 15-23.

Guetti, N. C. (2015). Preservação, salvaguarda e conservação arqueológica: a Reserva Técnica de Material Orgânico do departamento de arqueologia da UFPE. Clio Arqueológica, 30(2), 100-153.

Jones-Amin, H. (2014, setembro). Conservation of low-fired caution bay archaeological ceramics. In ICOM-CC 17th Triennial Conference Preprints, International Council of Museums, Paris.

Kuhl, B. M. (2006). Preservação do patrimônio arquitetônico da industrialização: problemas teóricos do restauro. Cotia, São Paulo: Ateliể Editorial.

Lagrou, E. (2010). Arte ou artefato? Agência e significado nas artes indígenas. PROA: Revista de Antropologia e Arte, 1(2).

Lima, H. P. (2019). Patrimônio para quem? Por uma arqueologia sensível. Habitus, 17(1), 25-37.

Lima, H. P., Barreto, C., \& Fernandes, C. (2018). Museus no século 21: ações pela salvaguarda e socialização do acervo arqueológico do Museu Goeldi. Revista do Patrimônio, 38, 145-161.

Lima, H. P., Moraes, B. M., \& Parente, M. T. V. (2013). "Tráfico" de material arqueológico, turismo e comunidades ribeirinhas: experiências de uma arqueologia participativa em Parintins, Amazonas. Revista de Arqueologia Pública, 7(2), 61-77. doi: https://doi.org/10.20396/rap.v7i2.8635692

Lima, H. P., \& Moraes, B. (2013). Arqueologia e comunidades tradicionais na Amazônia. Ciência e Cultura, 65(2), 39-42.

Lima, H. P., Barreto, C. N., \& Jaimes Betancourt, C. (2016). Novos olhares sobre as cerâmicas arqueológicas da Amazônia. In C. Barreto, H. P. Lima \& C. Jaimes Betancour (Orgs.), Cerâmicas arqueológicas da Amazônia: rumo a uma nova síntese (Vol. 1 , pp. 19-31). Belém: IPHAN.

Lima, S. C. (2002). Especificidades na restauração de cerâmicas arqueológicas: um estudo de caso. Revista do Museu de Arqueologia e Etnologia, (12), 269-281. doi: https://doi. org/10.11606/issn.2448-1750.revmae.2002.109453

Lima, S. C. (2016). A conservação de cerâmicas arqueológicas da Amazônia. In C. Barreto, H. P. Lima \& C. Jaimes Betancour (Orgs.), Cerâmicas arqueológicas da Amazônia: rumo a uma nova síntese (Vol. 1, pp. 543-550). Belém: IPHAN.

Linhares, A. M. A. (2017). Um grego agora nu: índios marajoara e identidade nacional brasileira. Curitiba: Editora CRV.

Lorêdo, W. M. (1994). Manual de conservação em arqueologia de campo. Rio de Janeiro: Instituto Brasileiro do Patrimônio Cultural.

Museu Paraense Emílio Goeldi (MPEG). (1986). São Paulo: Banco Safra. 
Natalio, F., Corrales, T. P., Wanka, S., Zaslanky, P., Kappl, M., Lima, H. P., . . Tremel, W. (2015). Siliceous spicules enhance fractureresistance and stiffness of pre-colonial Amazonian ceramics. Scientific Reports, 5, 13303. doi: https://doi.org/10.1038/srep13303

Portaria n. 375, de 19 de setembro de 2018. Institui a política de Patrimônio Cultural Material do IPHAN e dá outras providências. Recuperado de https://www.in.gov.br/materia/-/ asset_publisher/Kujrw0TZC2Mb/content/id/41601273/ do1-2018-09-20-portaria-n-375-de-19-de-setembrode-2018-41601031

Riegl, A. (2014). O culto moderno dos monumentos: a sua essência e origem (1 ed.). São Paulo: Editora Perspectiva S.A.

Rodrigues, S. F., \& Costa, M. L. (2016). Phosphorus in archeological ceramics as evidence of the use of pots for cooking food. Applied Clay Science, (123), 224-231. doi: https://doi. org/10.1016/j.clay.2015.10.038

Rodrigues, S. F., Costa, M. L., Pollmann, H., Kern, D. C., Silveira, M. I., \& Kipnis, R. (2015). Pre-historic production of ceramics in the amazon: provenience, raw materials, and firing temperatures. Applied Clay Science, 1007, 145-155.

Reserva Técnica Mário Ferreira Simões (RTMFS/MPEG). (n.d.). Ficha técnica dos trabalhos de conservação e restauração dos objetos arqueológicos. Belém [Banco de dados em Access, para uso interno. Curadoria da Reserva Técnica Mário Ferreira Simões/ Museu Paraense Emílio Goeldi].

Reserva Técnica Mário Ferreira Simões (RTMFS/MPEG). (2002). Resumo do trabalho de tratamento e conclusão das peças do Governo do Estado (2002). Belém. [Relatório para uso interno. Curadoria da Reserva Técnica Mário Ferreira Simões/Museu Paraense Emílio Goeldi].

Rye, O. S. (2007). Pottery technology: principles and reconstruction. Washington: Taraxacum.

Silva, F. A., \& Lima, S. C. (2015). Etnoarqueologia, conservação arqueológica e a compreensão dos processos de formação do registro arqueológico na Amazônia: a cerâmica arqueológica dos asurini do Xingu, PA. Revista de Arqueologia, 28(1), 123-142.
Simas, M. S. (2017a). Ficha de conservação e restauro número 19 referente ao objeto T 324. Belém. [Relatório para uso interno. Curadoria da Reserva Técnica Mário Ferreira Simões/Museu Paraense Emílio Goeldi].

Simas, M. S. (2017b). Conservar é conhecer: desafios à conservação das coleções arqueológicas e etnográficas do Museu Paraense Emílio Goeldi. Belém. [Relatório de bolsa referente ao Programa de Capacitação Institucional - PCI/MPEG/CNPq, não publicado]

Simas, M. S., Rosa, C., Barreto, C., \& Pinto, H. P. (2019). A fragment in each institution: the dispersion of Dita Acatauassu Marajoara Archaelogical Collection (Amazonia, Brazil). Conservar Património, 32, 79-86. doi: https://doi.org/10.14568/ cp2018038

Torelly, L. P. P. (2012). Patrimônio cultural: notas sobre a evolução do conceito. Arquitexto, (149).

Van Velthem, L. H. (2012). O objeto etnográfico é irredutível? Pistas sobre novos sentidos e análises. Boletim do Museu Paraense Emílio Goeldi. Ciências Humanas, 7(1), 51-66. doi: http://dx.doi. org/10.1590/S1981-81222012000100005

Van Velthem, L. H. (2019). Evocar outras realidades: considerações sobre as estéticas indígenas. In C. M. Damião \& C. Brandão (Orgs.), Estéticas Indígenas: III Colóquio de Estética da FAFIL UFG (pp. 15-32). Goiânia: Gráfica UFG.

Van Velthem, L. H., Pereira, E., \& Galucio, A. V. (2019). Acervos culturais do Museu Paraense Emílio Goeldi: 150 anos de história e perspectivas futuras. In A. V. Galúcio \& A. L. Prudente (Orgs.), Museu Goeldi: 150 anos de ciência na Amazônia (1 ed., Vol. 1, pp. 274-292). Belém: Museu Paraense Emílio Goeldi.

Viñas, S. M. (2010). Teoría contemporánea de la restauración. Madrid, Espanha: Editorial Sintesis.

\section{CONTRIBUIÇÃO DOS AUTORES}

L. P. Maia contribuiu com conceituação, investigação, metodologia, escrita (rascunho original); T. A. B. C. Sanjad com conceituação, investigação, metodologia, supervisão e escrita (revisão e edição); e H. P. Lima com conceituação e escrita (revisão e edição).

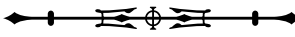

